\title{
PENINGKATAN PRODUKTIVITAS KELAPA SAWIT DENGAN PEMBERIAN PUPUK KOMPOS DAN BIOURINE SAPI DI DESA MARGO MULYO KABUPATEN BENGKULU TENGAH
}

\section{IMPROVEMENT OF PALM OIL PRODUCTIVITY BY GIVING FERTILIZER AND BIOURINE FERTILIZERS IN VILLAGE MARGO MULYO \\ CENTRAL BENGKULU DISTRICT}

\author{
Zul Efendi dan Erpan Ramon \\ Balai Pengkajian Teknologi Pertanian (BPTP) Bengkulu \\ J1. Irian KM 6,5 Kota Bengkulu \\ Email. fzulefendi@yahoo.com.
}

\begin{abstract}
ABSTRAK
Penelitian dilaksanakan di Desa Margo Mulyo Kecamatan Pondok Kubang Kabupaten Bengkulu Tengah pada bulan Agustus - Desember 2018. Penelitian bertujuan untuk mengetahui pengaruh pemberian pupuk kompos dan biourine terhadap produksi tandan buah segar kelapa sawit. Rancangan yang digunakan adalah Rancangan Acak Kelompok dengan 3 kelompok sebagai perlakuan dan 20 ulangan. Perlakuan Pertama (p1): tanpa pemupukan, perlakuan kedua (p2): dipupuk dengan kompos dan Perlakuan ketiga (p3): dipupuk dengan pupuk kompos dan biourine.variabel yang diamati adalah bobot tandan buah segar (TBS). Analisis data dilakukan dengan metode deskriptif. Hasil yang didapat adalah rata-rata produksi TBS p1 adalah 11,10 kg, p2 adalah 13,05 kg dan p3 adalah 13,59, sedangkan trend produksi tandan buah segar pada perlakuan p2 dan p3 memiliki kecendrungan peningkatan sedangkan p1 memiliki kecendrungan penurunan.
\end{abstract}

Kata Kunci: Produktivitas, Kelapa Sawit, Kompos dan Biourine, Margo Mulyo.

\begin{abstract}
The study was conducted in Margo Mulyo Village, Pondok Kubang District, Bengkulu Tengah Regency in August - December 2018. The study aimed to determine the effect of compost and biourine fertilizer on the production of fresh fruit bunches of oil palm. The design used was a Randomized Block Design with 3 groups as treatments and 20 replications. First treatment (p1): without fertilization, second treatment ( 2 2): fertilized with compost and third treatment (p3): fertilized with compost and biourine. The observed variables were weight of fresh fruit bunches (FFB). Data analysis was performed using descriptive methods. The results obtained are the average FFB production of p1 is $11.10 \mathrm{~kg}$, p2 is $13.05 \mathrm{~kg}$ and $\mathrm{p} 3 \mathrm{is} 13.59$, while the trend of production of fresh fruit bunches in $p 2$ and p3 treatments has an increased tendency while p1 has a decreased tendency.
\end{abstract}

Keywords: Productivity, Palm Oil, Compost and Biourine, Margo Mulyo. 


\section{PENDAHULUAN}

Luas areal perkebunan kelapa sawit di Indonesia tahun 2017 mencapai 12.307.677, dengan produksi minyak sawit sebesar 35.359.384 ton/th dan minyak kernel 7.071.877 ton/th (Ditjenbun, 2018). Sedangkan di Provinsi Bengkulu luas tanaman kelapa sawit pada tahun yang sama adalah 902.029 ha dengan produksi 902.432 ton/tahun. Perkebunan kelapa sawit di provinsi Bengkulu didominasi oleh perkebunan milik rakyat. Permasalahan perkebunan kelapa sawit tersebut adalah bibit yang ditanam tidak disertifikat, pemeliharaan minim dan pemupukan tidak dilakukan sebagaimana mestinya sehingga produksi tandan buah segar yang dihasilkan relatif rendah.

Produktivitas tanaman kelapa sawit yang baik dapat dicapai dengan pemeliharaan yang intensif. Salah satu sumber utama yang berpengaruh dalam pertumbuhan dan produktivitas kelapa sawit adalah pemupukan. Pemupukan merupakan pemberian 30 ember hara ke dalam tanah untuk menjaga keseimbangan hara yang dibutuhkan tanaman dan mengganti hara yang hilang terbawa hasil panen.

Menurut Poeloengan et al. (2003)

dalam Panggabean dan Purwono (2017) pemupukan menjadi satu keharusan karena kelapa sawit tergolong tanaman yang sangat konsumtif. Kekurangan salah satu hara akan segera menunjukkan gejala defisiensi dan mengakibatkan pertumbuhan terhambat serta produksi menurun. Selanjutnya Adiwiganda (2007) menyatakan bahwa upaya pemupukan pada tanaman kelapa sawit harus dapat menjamin pertumbuhan dan yang normal sehingga dapat memberikan produksi tandah buah segar (TBS) yang optimal serta menghasilkan minyak sawit mentah (CPO) yang tinggi baik kuantitas maupun kualitasnya.

Penggunaan pupuk anorganik yang berlebihan menyebabkan beberapa masalah pada tanah dan dapat mencemari air sehingga keseimbangan alam menjadi terganggu (Indriani, 2011). Penggunaan pupuk anorganik untuk meningkatkan produktivitas tanaman dapat ditekan dengan beralih menggunakan pupuk organik (kompos dan biourine). Biourin dapat memberikan peningkatan hasil tanaman yang menyamai bahan penyubur tanaman (BPT) (Perdana, 2015). Kurniadinata (2007), menyatakan bahwa penggunaan urin sapi sebagai pupuk akan memberikan keuntungan diantaranya harga murah, mudah didapat dan diaplikasikan, serta memiliki kandungan hara yang dibutuhkan tanaman. Pupuk urin 
sapi mengandung tertentu yang dapat merangsang perkembangan tanaman dan mengandung lebih banyak $\mathrm{N}$ dan $\mathrm{K}$ dibandingkan dengan pupuk kandang sapi padat (Aisyah et al., 2011). Penelitian ini bertujuan untuk mengetahui pengaruh pemberrian pupuk kompos dan biourine terhadap produksi tandan buah segar kelapa sawit.

\section{METODE PENELITIAN}

Penelitian ini dilaksanakan di Desa Margo Mulyo Kecamatan Pondok Kubang Kabupaten Bengkulu Tengah pada bulan Agustus - Desember 2018. Rancangan yang digunakan adalah Rancangan Acak Kelompok dengan 3 (tiga) perlakuan dan 20 (dua puluh) ulangan. Perlakuan pertama (p1) adalah kelapa sawit tidak dipupuk, perlakuan kedua (p2) adalah kelapa sawit dipupuk dengan kompos sebanyak 80 $\mathrm{kg} /$ pohon dan perlakuan ketiga (p3) adalah kelapa sawit dipupuk dengan pupuk kompos sebanyak $80 \mathrm{~kg} /$ pohon dan biourine 5 liter/pohon. Kelapa sawit yang digunakan adalah kelapa sawit yang sudah berproduksi, berumur 8 tahun sebanyak 60 batang.

Sebelum dilakukan pemupukan, terlebih dahulu dilakukan pembersihan piringan disekitar batang kelapa sawit dan gulma yang menempel pada batang kelapa sawit. Aplikasi pupuk kompos dan biourine dilakukan dengan menaburkan pupuk dikeliling piringan kelapa sawit yang sudah dibersihkan. Parameter yang diukur adalah produksi tandan buah segar (TBS) kelapa sawit yang diukur setelah 2 bulan setelah pemupukan dilakukan. Data yang diperoleh di tabulasi dan diolah secara deskriptif.

Cara pembuatan kompos: bahan yang digunakan adalah feces sapi, mollases, aktivator dan kapur dan air secukupnya. Bahan aktivator, tetes dan kapur dilarutkan dengan air sehingga membentuk larutan. Kemudian bahan tersebut disiramkan pada bahan utama yaitu feces sapi, kemudian diaduk sampai rata. Setelah bahan tercampur rata, langsung dilakukan penutupan dengan terpal agar terhindar dari udara bebas dan sinar matahari langsung. Bahan di fermentasi selama 21 hari dan setiap minggunya dilakukan pengadukan agar proses fermentasi berlangsung dengan baik. Setelah 21 hari maka bahan dibuka dan dimasukkan kedalam karung untuk digunakan untuk pemupukan.

Cara pembuatan biourine sapi: bahan yang digunakan adalah urine sapi 100 liter, aktivator $250 \mathrm{ml}$, tetes $750 \mathrm{ml}$, empon-empon $5 \mathrm{~kg}$ dan air secukupnya. Bahan (empon-empon, ditumbuk hingga 
halus, untuk selanjutnya masukkan kedalam wadah, bersama aktivator dan mollases dan ditambahkan dengan air dan aduk hingga larut. Setelah itu, larutan tersebut dimasukkan kedalam urine sapi. Aduk hingga tercampur rata, dan setelah itu bahan biourine dapat disimpan selama 21 hari. Setelah 21 hari biourine dapat digunakan sebagai pupuk untuk tanaman. Sebelum diaplikasikan pada tanaman, sebaiknya dilakukan penganginan terlebih dahulu kandungan amoniak yang ada pada biourine menjadi berkurang.

\section{HASIL DAN PEMBAHASAN}

\section{Karakteristik Wilayah}

Desa Margo Mulyo terletak pada bagian Utara wilayah Kecamatan Pondok Kubang Kabupaten Bengkulu Tengah. Sebelah Utara Desa tersebut berbatasan dengan desa Harapan Makmur Kecamatan Pondok Kubang Kabupaten Bengkulu Tengah. Bagian Barat Desa ini terletak pada daerah yang bergelombang yang berbatasan dengan Desa Tanjung Terdana dan Dusun Barun I Kecamatan Pondok Kubang Kabupaten Bengkulu Tengah. Sebelah Selatan desa ini berbatasan dengan Desa Taba Pasma Kecamatan Talang Empat Kabupaten Bengkulu Tengah. Sebelah Timur Desa ini berbatasan dengan Desa
Kembang Seri Kecamatan Talang Empat Kabupaten Bengkulu Tengah, yang sebagian besar pada wilayah ini masih semak belukar.

Luas wilayah Margo Mulyo Lebih Kurang 455 hektar yang terdiri dari lahan basah 114 ha dan lahan kering 341 ha. Adapun jenis tanaman holtikultura yang dikembangkan oleh para petani di Desa Margomulyo adalah Padi sawah, palawija, dan lain-lain. Sedangkan tanaman perkebunan yang diusahakan antara lain Kopi, kelapa hibrida, karet, kelapa sawit dan lain - lain.

Topografi Daerah ini berada diketinggian 800 Meter diatas permukaan laut dengan topografi bergelombang. Jenis tanah di Desa Margo Mulyo terdiri atas Podsolik Merah Kuning, dan sisanya gambut (Hidromorf). Berdasarkan pembagian type iklim menurut oldeman, type Desa Margo Mulyo adalah type E3. Musim hujan pada Bulan Oktober sampai dengan Maret dan kemarau pada bulan April sampai dengan September. Penyebaran hujan tidak merata sepanjang tahun dan hujan paling banyak jatuh pada Bulan Desember. Rata - rata hujan selama 10 tahun terakhir ini berkisar pada 2.850 $\mathrm{ml} /$ tahun dengan 166 hari hujan. Jumlah curah hujan selama tahun 2008 adalah 
$2.450 \mathrm{~mm}$ dengan 157 hari hujan. Suhu rata-rata 26 derajat celcius dengan suhu maksimum 33 derajat celcius dan suhu minimum 21 derajat celcius, kelembaban suhu rata-rata $81 \%$

Sektor pertanian merupakan sumber andalan di Desa Margo Mulyo para petani pada umumnya mengusahakan tanaman buah-buahan dan tanam perkebunan lainnya, disamping tanaman padi dan palawija. Tanaman buah - buahan saat ini yang dominan adalah rambutan dan sebagian kecil durian. Hal ini ditunjang dengan adanya kelompok - kelompok tani yang ada di Desa Margo Mulyo. Tanaman perkebunan saat ini mendapatkan prioritas oleh para petani hal ini ditunjukkan dengan luasnya tanaman karet dan sawit di samping tanaman kelapa hibrida yang ditanam di setiap pekarangan penduduk masing - masing minimal 5 batang

\section{Produksi Tandan Buah Segar Kelapa Sawit}

Dari hasil diperoleh bahwa rata-rata produksi tandan buah segar kelapa sawit yang diberi pupuk kompos dan biourine lebih tinggi bila dibandingkan dengan tandan buah segar kelapa sawit yang tidak diberi pupuk dan yang hanya diberikan pupuk kompos saja. Sedangkan rata-rata tandan buah segar kelapa sawit yang diberi pupuk kompos lebih tinggi bila dibandingkan dengan tandan buah segar kelapa sawit yang tidak diberikan pupuk sama sekali. Tingginya produksi tandan buah segar kelapa sawit yang diberikan pupuk kompos dan biourine menjadi 33 ember $33 \quad 33 \mathrm{r}$ bahwa tanaman mendapatkan hara yang cukup setelah penambahan kompos dan biourine maupun tanaman yang mendapatkan kompos bila dibandingkan dengan kelapa sawit yang tidak mendapatkan pupuk sama sekali, sehingga diduga ada peningkatan 33ember hara dalam tanah yang disebabkan oleh kandungan C-organiknya. Selanjutnya kandungan 33ember $\mathrm{N}$ yang tinggi ternyata mampu mempengaruhi peningkatan jumlah daun sehingga mengoptimalkan proses fotosintesis tanaman Hal ini juga sejalan dengan hasil penelitian Assmann et. Al., (2013) yang mengungkapkan bahwa pupuk 33 ember 3333 ember pengaruh terhadap peningkatan kandungan $\mathrm{C}$-organik dan $\mathrm{N}$ tanah masing-masing sebesar 3,65 - 4,94 mg/ha/tahun dan 216 - $272 \mathrm{~kg} / \mathrm{ha} /$ tahun. Sementara itu, hasil penelitian Costa et. Al., (2013) juga menunjukkan bahwa kandungan $\mathrm{P}$ tersedia dalam tanah akan meningkat dengan menambahkan pupuk kotoran sapi (kompos) dalam tanah. Unsur $\mathrm{P}$ ini berperan dalam meningkatkan bobot 
buah pada tanaman. Rata-rata produksi tandan buah segar kelapa sawit yang tidak diberikan pupuk, yang diberikan puuk kompos dan yang diberikan pupuk kompos dan biourine dapat dilihat pada Tabel 1 .

Dari Tabel 1 dapat dilihat bahwa kelapa sawit yang dberi pupuk kompos dan biourine dapat memberikan produksi ratarata tandan buah segar kelapa sawit yang paling tinggi bila dibandingkan dengan kedua perlakukan lainnya. Hal ini menandakan kombinasi unsur $\mathrm{P}$ yang terdapat didalam pupuk kompos dan biourine berperan dalam meningkatkan bobot tandan buah segar kelapa sawit. Pupuk kompos dan biourine juga berperan dalam memperbaiki struktur tanah perkebunan kelapa sawit. Struktur tanah yang membaik akibat penambahan kompos akan mempermudah akar kelapa sawit menembus ke dalam tanah. Hal ini dibuktikan dengan system perakaran yang lateral yang dimiliki oleh kelapa sawit ini akan memudahkan akar mencari sumber hara dan dengan mudah dapat menembusnya . Sementara kompos dan biourine yang juga berperan sebagai amelioran mampu meningkatkan $\mathrm{pH}$ tanah menjadi relatif stabil antara 5-6. Kondisi ini mampu menciptakan hara secara makro dan mikro serta mikroba yang baik tersedia di sekitar perakaran tanaman. Kompos yang baik adalah yang memiliki $\mathrm{C} / \mathrm{N}$ rasio yang rendah $(<20)$, karena hal itu dapat meningkatkan kadar N, K2O, P2O5, Ca dan $S$ tersedia dalam tanah sehingga dapat meningkatkan produksi (Wigena et. al., 2009).

Tabel 1 Rata-rata Produksi Tandan Buah Segar Kelapa Sawit yang tidak diberi Pupuk (p1), yang diberi Pupuk Kompos (p2) dan yang diberi Pupuk Kompos dan Biourine (p3)

\begin{tabular}{cccc}
\hline Panen ke & \multicolumn{3}{c}{ Perlakuan } \\
\cline { 2 - 4 } & Pertama (p1) kg & Kedua (p2) kg & Ketiga (p3) kg \\
\hline 1 & 12,85 & 10,79 & 10,93 \\
2 & 11,41 & 11,40 & 11,83 \\
3 & 10,40 & 13,51 & 13,22 \\
4 & 10,14 & 14,60 & 15,40 \\
5 & 10,70 & 15,00 & 16,55 \\
\hline Total & 55,50 & 65,29 & 67,93 \\
\hline Rata-rata & 11,10 & 13,05 & 13,59 \\
\hline
\end{tabular}


Trend Produksi Tandan Buah Segar (TBS) Kelapa Sawit

Trend produksi tandan buah segar kelapa sawit yang tidak diberikan pupuk (p1), diberikan pupuk kompos (p2) dan diberikan pupuk kompos dan biourine (p3) dapat dilihat pada Grafik 1. Trend produksi tandan buah segar kelapa sawit yang diberikan pupuk kompos (p2) dan kelapa sawit yang diberikan pupuk kompos dan biourine (p3) memiliki kecendrungan mengalami peningkatan setiap kali panen, sedangkan trend produksi tandan buah segar kelapa sawit yang tidak diberikan pupuk memiliki kecendrungan menurun.

Sedangkan produksi tandan buah segar kelapa sawit yang diberikan pupuk kompos dan biourine (p3) memiliki trend yang lebih baik dimana pada penen ke-4 dan ke-5 sudah menampakkan perbedaan, sehingga diharapkan pada panen selanjutnya akan terjadi peningkatan lagi.

\section{Grafik 1}

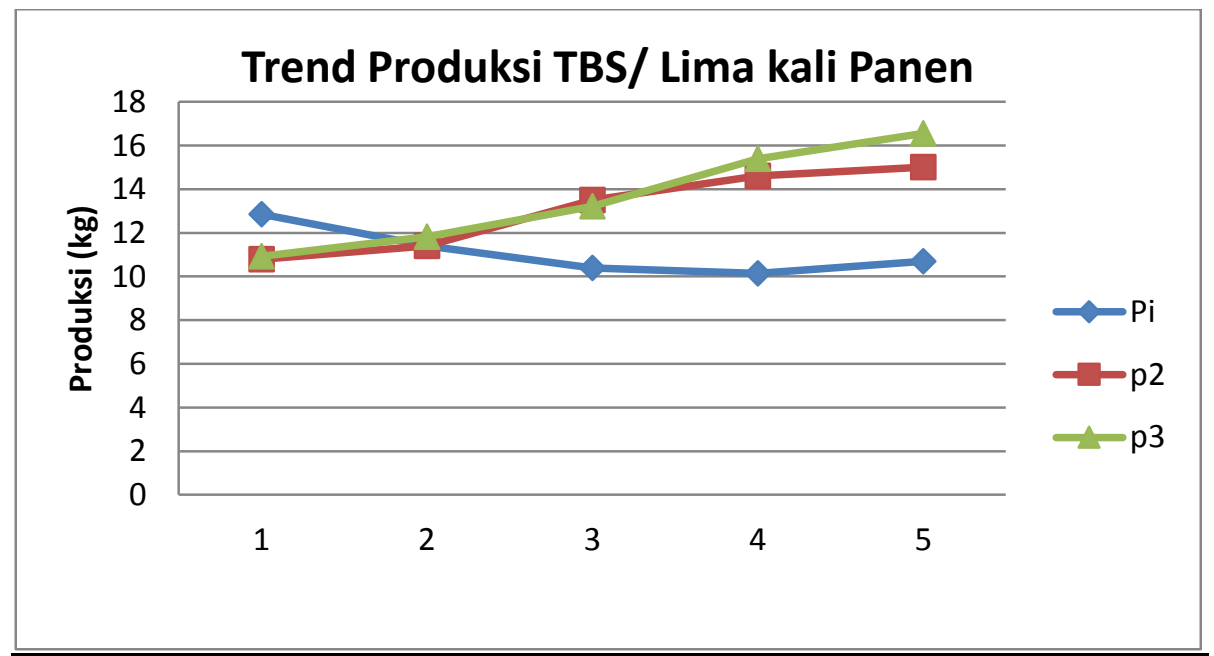

Keterangan:

P1: tanpa pupuk

P2: dipupuk dengan kompos

P3: dipupuk dengan kompos dan biourine 


\section{KESIMPULAN}

Pemberian pupuk kompos sebanyak

$80 \mathrm{~kg} /$ pohon dan biourine sebanyak 5 liter/pohon dapat meningkatkan produksi tandan buah segar dan trend produksi kelapa sawit lebih baik bila dibandingkan dengan tandan buah segar kelapa sawit yang tidak diberikan pupuk.

\section{DAFTAR PUSTAKA}

Adiwiganda, R. 2007. Manajemen Tanah dan Pemupukan Kelapa Sawit. Dalam S. Mangoensoekarjo (Ed.). Manajemen Tanah dan Pemupukan Budidaya Tanaman Perkebunan. Yogyakarta (ID) : Gajah Mada University Press.

Aisyah, S., N. Sunarlim, B. Solfan. 2011.Pengaruh urine sapi terfermentasi dengan dosis dan interval pemberian yang berbeda terhadap pertumbuhan tanaman sawi (Brassica juncea L.). Jurnal Agroteknologi. 2(1): 1-5.

Assmann, JM et. al., 2013. Soil Carbon and Nitrogen Stocks and Fractions in a Long-Termintegrated CropLivestock System under No-Tillage in Southern Brazil.Agriculture, Ecosystems and Environment -4551; P: 8

Badan Pusat Statistik Propinsi Bengkulu 2018, Bengkulu Dalam Angka.

Costa, S.E.V.G.A., et al., Impact of an Integrated No-Till Crop-Livestock System on Phosphorus Distribution, Availability and Stock. Agriculture, Ecosystems and Environment
(2013),

http://dx.doi.org/10.1016/j.agee.201

3.12 .001

Ditjenbun, 2018. Statistik Perkebunan Indonesia, Kelapa Sawit 20152017. Direktorat Jenderal Perkebunan. Kementerian Pertanian. Jakarta.

Indriani, Y.H. 2011. Membuat Kompos Secara Kilat. Penebar Swadaya. Jakarta.

Kurniadinata, O.F. 2007. Pemanfaatan feses urin sapi sebagai pupuk organik dalam perkebunan kelapa sawit. Seminar Optimalisasi Hasil Samping Perkebunan Kelapa Sawit dan Industri Olahannya sebagai Pakan Ternak. Paser, Kalimantan Timur. Juli 2007: 65-72.

Panggabean. S.Manahan dan Purwono 2017. Manajemen Pemupukan Tanaman Kelapa Sawit (Elaeis Guineensis Jacq.) Di Pelantaran Agro Estate, Kalimantan Tengah. Management of oil palm fertilizationin Pelantaran Agro Estate, Center Kalimantan. Buletin Agrohorti 5 (3): 316 -324 2017.

Perdana, S.N., W.S. Dwi, M. Santoso. 2015. Pengaruh aplikasi biourin dan pupuk terhadap pertumbuhan dan hasil tanaman bawang merah (Allium ascalonicum L.). J. Prod. Tan. 3(6): 457-463.

Wigena, I.G.P., Sudradjat, Santun R.P. Sitorus dan H. Siregar, 2009. Karakterisasi Tanah dan Iklim serta Kesesuaiannya untuk Kebun Kelapa Sawit Plasma di Sei Pagar, Kabupaten Kampar, Provinsi Riau. Jurnal Tanah dan Iklim No. 30, Desember 2009. Hal: 1-16 